\title{
Hygrothermal deterioration in carbon/epoxy and glass/ epoxy composite laminates aged in marine-based environment (degradation mechanism, mechanical and physicochemical properties)
}

\author{
Pouyan Ghabezi ${ }^{1,3,4, \star}$ (1) and Noel M. Harrison ${ }^{1,2,3,4}$ \\ ${ }^{1}$ IComp Irish Composites Centre, Dublin, Ireland \\ ${ }^{2}$ I-Form Advanced Manufacturing Research Centre, Dublin, Ireland \\ ${ }^{3}$ Mechanical Engineering, National University of Ireland Galway, Galway, Ireland \\ ${ }^{4}$ Ryan Institute for Environmental, Marine and Energy Research, NUI Galway, Galway, Ireland
}

Received: 3 November 2021

Accepted: 11 January 2022

Published online:

27 January 2022

(C) The Author(s) 2022

\begin{abstract}
One of the major challenges in off-shore tidal and wave energy devices is the ageing of these structures in the hostile marine environment, which limits their operating life. In this research, mechanical properties of aged glass/epoxy and carbon/epoxy composite specimens including tensile strength, Young's modulus, flexural strength, and shear strength, following immersion in a representative accelerated marine degradation environment (artificial seawater, with $3.5 \%$ salinity at room temperature and $60^{\circ} \mathrm{C}$ ) have been investigated. The microstructure and physicochemical characterization of the aged samples were assessed via microscopic imaging, micro-CT scanning and differential scanning calorimetry. The degradation phenomenon was apparent in the change of mechanical properties and microstructure of composite laminates (micro-cracks and debonding between matrix and fibre). Generally, the ageing process had a more severe effect on tensile and shear strengths of glass/epoxy samples than those of carbon/epoxy specimens. Reversely, the results of bending tests of carbon/epoxy composites showed more drop-in flexural properties than glass/ epoxy samples. The results revealed that degradation mechanisms continue even after reaching the saturation point in composite materials. The achievements of this research present a good understanding of the effect of degradation of composite materials in salt water to deal with their application in real service environment.
\end{abstract}

Handling Editor: Chris Cornelius.

Address correspondence to E-mail: pouyan.ghabezi@nuigalway.ie 


\section{Introduction}

The European Union has set a target of an $80 \%$ reduction in carbon emissions by 2050 [1], which will see an intensive reduction in the reliance on fossil fuel combustion. Marine renewable energy, in the form of off-shore tidal and wave energy devices, holds massive potential in replacing fossil fuel-based electricity generation. However, one of the major challenges associated with their widespread implementation is the ageing/degradation of these structures in the hostile marine environment, which limits their operating life $[2,3]$. The structures made of composite materials such as tidal turbine blades exist in harsh aqueous environments such as the sea, where the chemistry of the aqueous environment alongside the complex dynamic forces play a significant role in material degradation. Composite material ageing in the marine environment is mainly attributed to moisture ingress and is driven by both chemical- and mechanical-based mechanisms [4]. Most polymer matrix composites will absorb small, but potentially damaging amounts of moisture from the surrounding environments with the degree of degradation (knock-down in material property) that occurs being linked directly with the quantity of moisture absorbed.

Some researchers have investigated the effect of accelerated temperature on the mechanical properties of composite materials immersed in salt water [5-10]. Kant and Penumadu [11] assessed the change in tensile strength and fracture toughness of carbon fibres exposed to seawater during 120 days at $40{ }^{\circ} \mathrm{C}$ and $80^{\circ} \mathrm{C}$ temperatures with regular testing intervals. The effect of adding chain extender during the production of poly (lactic acid) (PLA) films on the hydrolytic degradation of the films was evaluated by Limsukon et al. [12] at temperatures from 40 to $95{ }^{\circ} \mathrm{C}$. Tserpes et al. [13] have investigated the effect of hygrothermal (temperature and humidity) ageing on the interlaminar shear strength of a carbon fibre/ epoxy resin bio-composite experimentally.

The degradation process is analyzed by nuclear magnetic resonance (NMR) spectroscopy, which identifies and quantifies intermediates and degradation product(s). Bauer et al. [14] have investigated the hydrolytic degradation of two most frequently used polyphosphoesters, poly (methyl ethylene phosphate) (PMEP) and poly (ethyl ethylene phosphate)
(PEEP). The degradation process was analyzed by NMR spectroscopy, which identifies and quantifies intermediates and degradation product(s). The effect of moisture is to lead hydrolytic breakdown of the interface between fibre and matrix causing a loss in the performance of load transfer from matrix to fibre [15]. Gagani et al. [15] investigated the combined effect of water immersion and temperature on the interlaminar shear static and fatigue strength of I-beam-shaped glass fibre epoxy composites. They presented an analytical model based on Arrhenius theory for building a fatigue master curve that accounts for both temperature and water immersion. Oxidation is generally considered to be the most serious issue when using polymers at elevated temperatures with the rate of degradation increasing with the amount of oxygen amount $[16,17]$.

Although the degradation in composite materials can be considerable, it typically is a slow process, leading to challenges for in-lab recreation of in-service conditions. As a result, acceleration degradation conditions are used however, for this to be valid, it is essential to know the degradation mechanisms involved and thus both physicochemical and mechanical test data are required [18]. Wang et al. [19] have studied the degradability of poly (glycerol maleate) (PGM) in various aqueous environments to evaluate the influence of salinity and microorganisms on the degradation. PGM films are immersed in reverse osmosis water, fresh water, tap water, artificial seawater, and seawater at $25{ }^{\circ} \mathrm{C}$ for 56 days. Chakraverty et al. [20] showed a loss in both stress and strain at rupture in glass fibre reinforced polymer composites for a period of one year immersed in seawater. The greater percentage of glass transition temperature $(\mathrm{Tg})$ reduction for composite laminates subjected to hygrothermal treatment is because of more damaging effects along with plasticization and swelling of epoxy polymer (mechanical-based degradation) as a result of hygro-elastic swelling stress [21].

This research presents accelerated ageing on glass/ epoxy and carbon/epoxy samples in artificial seawater immersion at room and elevated temperatures (over 180 days). These accelerated tests were used to evaluate the performance of composite materials, components, and/or structures used in marine-based applications through tensile, inter-laminar shear strength, three-point bending tests, microstructure, and microscopic assessment, and water content 
measurement. One of the most wide applications of composite materials is the use of them as tidal turbine blades in the harsh environment of seawater which needs composite laminates with a combination of different fibre angles, materials, stacking, and so on to resist against the mixed loads (normal loads, shear loads, fatigue loads, etc.) applied by waves. Therefore, in this work, biaxial glass reinforcement with $\pm 45^{\circ}$ fibre orientation and a combination of different carbon fibre textures were selected along with an epoxy matrix. To predict the long-term life of composite materials based on the data collected from the accelerated testing, it is necessary to have a good understanding of the effect of seawater and ageing process on mechanical properties and physicochemical characterization of composite laminates as well as the ageing and degradation mechanisms. Generally, the novelties of this work can be summarized as:

A full test framework to investigate the ageing process in composite materials with different textures, assessment the effect of degradation on glass/ epoxy and carbon/epoxy samples over time in term of tensile strength, tensile modulus, flexural properties, shear strength, etc., investigation of the relation between the water content in composite samples and change in their mechanical properties, investigation of the effect of ageing time on mechanical properties before and after saturation time (when there is no more additional water uptake in composite samples) in order to assess the contribution of mechanicalbased damages such as plasticization and debonding between fibre and matrix (water uptake, osmotic process and capillary phenomenon) and/or chemical-based damages (the reaction between matrix and seawater), evaluation the effect of seawater on tensile modulus (simultaneous change in tensile strength and strain), and understanding change in glass transition temperature during ageing process at elevated temperatures (different trends are reported by researchers).

\section{Materials and characterization}

Six layers of Biaxial glass reinforcement with $\pm 45^{\circ}$ fibre orientation $(2.9 \mathrm{~mm}$ thickness) and surface density $320 \mathrm{~g} / \mathrm{m}^{2}$ (Table 1) suitable for use in a wide range of glass-reinforced composite applications were used as reinforcing in EL2 epoxy AT30 FAST (Easy Composites Ltd, Staffordshire, UK, product
Table 1 Biaxial glass fabric-320 g [24]

\begin{tabular}{lll}
\hline Fibre orientation & Surface density $\left(\mathrm{g} / \mathrm{m}^{2}\right)$ & Material \\
\hline$+45^{\circ}$ & 156 & E-glass 200 TEX \\
$90^{\circ}$ & 1 & E-glass 200 TEX \\
$0^{\circ}$ & 1 & E-glass 200 TEX \\
$-45^{\circ}$ & 156 & E-glass 200 TEX \\
\hline
\end{tabular}

code: EP-L2-F-05) laminating resin (Table 2). The panel was manufactured using the hand lay-up method. A simple and very effective post-cure cycle was used with the EL2 epoxy laminating resin ( $24 \mathrm{~h}$ at room temperature and then $6 \mathrm{~h}$ at $60^{\circ} \mathrm{C}$ ) in compliance with the material datasheet [24]. In addition, an industry sourced (Easy Composites Ltd, Staffordshire, UK) high strength carbon fibre/epoxy resin sheet (CFS-RI-2-1900, $2 \mathrm{~mm} \times 2000 \mathrm{~mm} \times 950$ $\mathrm{mm}$ ) [24], cured under pressure at elevated temperature to produce a carbon fibre sheet with engineering-grade mechanical properties and a class- $A$ surface finish, was obtained. The balanced laminates (stacking) were selected. This means that the fibre type, weight and weave were symmetrical from the front to the back ply (Table 3). Water ageing is commonly accelerated using the time-temperature equivalence principle by raising the temperature of water baths [22]. Laboratory manufactured seawater, with $3.5 \%$ salinity (the average ocean surface salinity [23]) was prepared (35 g of table salt provided from local stores plus tap water up to a total mass was $1000 \mathrm{~g}$, stirring until the salt was completely dissolved in the water.

Tap water often contains lots of natural minerals found in seawater, such as magnesium and calcium. For ageing process on composite laminates, a waterheating WiseCircu bath (EDHWCB-11 and EDHWCB-22, Seoul, South Korea) with circulating pump was used for a continuous testing condition at $60{ }^{\circ} \mathrm{C}$, and a plastic box for room temperature aged composite samples (the average room temperature, $23^{\circ} \mathrm{C}$, was measured by a temperature/humidity meter).

The water uptake measurement was done in compliance with ASTM D 5229 standard (Procedure A) [25] to calculate the diffusivity based on Fickian's second law at room and elevated temperatures. To do this, five $100 \pm 10 \mathrm{~mm}$ square sheets (glass/epoxy and carbon/epoxy) were cut and sealed with 
Table 2 Mechanical properties of EL2 epoxyAT30 FAST laminating resin [24]

\begin{tabular}{lllll}
\hline Property & Units & Resin & Hardener & Combined \\
\hline Viscosity @20 ${ }^{\circ} \mathrm{C}$ & $\mathrm{mPa}$ & $1200-1800$ & $5-80$ & - \\
Density @20 $20 \mathrm{C}$ & $\mathrm{g} / \mathrm{cm}^{3}$ & $1.13-1.17$ & $0.90-1.06$ & $1.05-1.15$ \\
Hardness & Shore D & & & $85-89$ \\
Linear shrinkage & $\%$ & & & 0.5 \\
Tensile strength & $\mathrm{MPa}$ & & & $67.0-75.0$ \\
Elongation at break & $\%$ & & $6.0-8.0$ \\
Flexural strength & $\mathrm{MPa}$ & & $120-130$ \\
Flexural modulus & $\mathrm{MPa}$ & & $3600-4000$ \\
\hline
\end{tabular}

Table 3 Carbon/epoxy composite stacking layers with $2 \mathrm{~mm}$ thickness [24]

\begin{tabular}{lc}
\hline Surface density $\left(\mathrm{g} / \mathrm{m}^{2}\right)$ & Type \\
\hline 200 & $2 / 2$ Twill $3 \mathrm{k}$ carbon \\
300 & -45 Biaxial carbon \\
650 & $2 / 2$ Twill carbon \\
300 & -45 Biaxial carbon \\
200 & $2 / 2$ Twill $3 \mathrm{k}$ carbon \\
\hline
\end{tabular}

stainless steel foil bonded to the edges such that moisture absorption through the edges was minimised (Fig. 1). The initial weights of the five water uptake composite samples were measured using digital scales to calculate moisture absorption content. The samples were kept in the salt water for about nine months at room temperature and $60{ }^{\circ} \mathrm{C}$. The final weights of the samples were measured every week.

The absorption (weight gain) curves were plotted against the square root of time. These curves for both temperatures present an initial linear response at short times followed by a non-linear behaviour at larger times until achieving a saturation level. The saturation occurred at moisture content $1.13 \%$ for glass/epoxy samples after $1918 \mathrm{~h}$ at $60^{\circ} \mathrm{C}$, and $5876 \mathrm{~h}$ at room temperature. For the carbon/epoxy samples, saturation occurred at moisture content $0.61 \%$ after $1008 \mathrm{~h}$ at $60{ }^{\circ} \mathrm{C}$, and $1727 \mathrm{~h}$ at room temperature. However, the curve corresponding to each temperature showed a different pattern of behaviour due to differences in their void content, fibre volume fraction, manufacturing methods, type of epoxies used, etc. (discussed in the following sections). Table 4 compares the diffusivity (D) in composite specimens at room temperature and $60^{\circ} \mathrm{C}$.

\section{Results and discussion}

\section{Mechanical testing}

The characterization of elastic properties of glass/ epoxy and carbon/epoxy laminates (the average value of five tested samples) was performed using a hydraulic Instron 8800 tensile test machine and a clipon Instron extensometer (dynamic, travel length: $5 \mathrm{~mm}$ ), according to ASTM D3039 [26], before and after seawater ageing at room temperature and $60{ }^{\circ} \mathrm{C}$. The tensile strength and elastic modulus in glass/ epoxy were determined as a mean value of $106.33 \pm 1.7 \mathrm{MPa}$ and $6.8 \pm 0.3 \mathrm{GPa}$, respectively, for
Figure 1 Sealed water uptake samples.
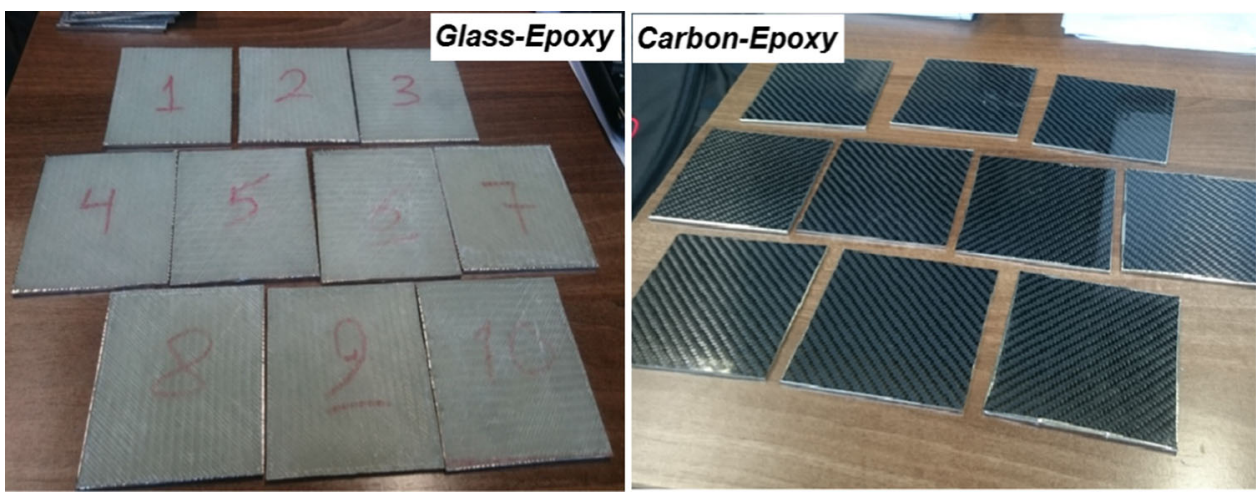
Table 4 Diffusivity in glass/ epoxy and carbon/epoxy

\begin{tabular}{|c|c|c|c|c|}
\hline \multirow[t]{2}{*}{ Material } & \multicolumn{2}{|c|}{ Diffusivity (D) $\mathrm{mm}^{2} / \mathrm{s}$} & \multicolumn{2}{|l|}{ Solubility (mass \%) } \\
\hline & Room temperature & $60^{\circ} \mathrm{C}$ & Room temperature & $60{ }^{\circ} \mathrm{C}$ \\
\hline Glass/epoxy & $4.9 \mathrm{E}-8$ & $3.8 \mathrm{E}-7$ & 1.13 & 1.13 \\
\hline Carbon/epoxy & $2.0 \mathrm{E}-07$ & $8.3 \mathrm{E}-07$ & 0.61 & 0.61 \\
\hline
\end{tabular}

dry (reference) specimens (Figs. 2 and 3). The effect of seawater on tensile strength of glass/epoxy at room temperature after $45(105.03 \pm 2 \mathrm{MPa}), 90$ $(104.4 \pm 2 \mathrm{MPa})$ and $180(102.24 \pm 2 \mathrm{MPa})$ days were slight, so that after 180 days, $1.81 \%$ loss was observed in tensile strength. However, submersion in elevated temperatures has affected the tensile strength significantly. Mean tensile strength at $60{ }^{\circ} \mathrm{C}$ after 45 days immersion in salt water was $83.66 \pm 2 \mathrm{MPa}$. Continuing the water immersion in the salt water showed more reduction in the tensile strength of glass/epoxy specimens as $79 \pm 1.8 \mathrm{MPa}$ after 90 days, whereas this value decreased to $77.77 \pm 1.5 \mathrm{MPa}$ after 180 days. Figure 3 illustrates the change in Young's modulus over ageing process after $45(6.84 \pm 0.3$ $\mathrm{GPa}), 90(6.88 \pm 0.3 \mathrm{GPa})$, and $180(6.88 \pm 0.3 \mathrm{GPa})$ days at room temperature indicating no significant change in this value for glass/epoxy composites, with the reference/dry sample value being $6.8 \pm 0.3$ GPa. Also, Fig. 3 indicates that the ageing process on glass/epoxy composite sheets at $60{ }^{\circ} \mathrm{C}$ shows a fluctuation in Young's modulus, $6.61 \pm 0.3 \mathrm{GPa}$ after
45 days, $6.3 \pm 0.3 \mathrm{GPa}$ after 90 days, and $6.44 \pm 0.3$ GPa after 6 months.

In the same way, tensile strength and elastic modulus were determined, obtaining a mean value of $532.64 \pm 2 \mathrm{MPa}$ and $38.9 \pm 1.3 \mathrm{GPa}$, respectively, for dry carbon/epoxy specimens (Figs. 4, 5). The tensile strength and elastic modulus were $475.77 \pm 2.1 \mathrm{MPa}$ and $39.1 \pm 1 \mathrm{GPa}$ for aged carbon/epoxy specimens at $60{ }^{\circ} \mathrm{C}$, respectively, after 45 days. The effect of seawater on tensile strength after 90 days $(459 \pm 2.5$ $\mathrm{MPa})$ and $180(428 \pm 2 \mathrm{MPa})$ days at elevated temperature was significant. A rise in tensile elastic modulus due to seawater ageing, $6.6 \%$ at an elevated temperature after 90 days, and $7.96 \%$ after 180 days were observed.

Failure modes and location of failure in the aged and dry composite samples were recorded using the three-part failure mode code according to ASTM D3039 standard. It is worth noting that dry samples demonstrated lateral gage middle (LGM) and angled gage middle (DGM) failure modes, while the ageing process and degradation in the composite specimens

\section{Glass/Epoxy Samples \\ nGlass-Epoxy}

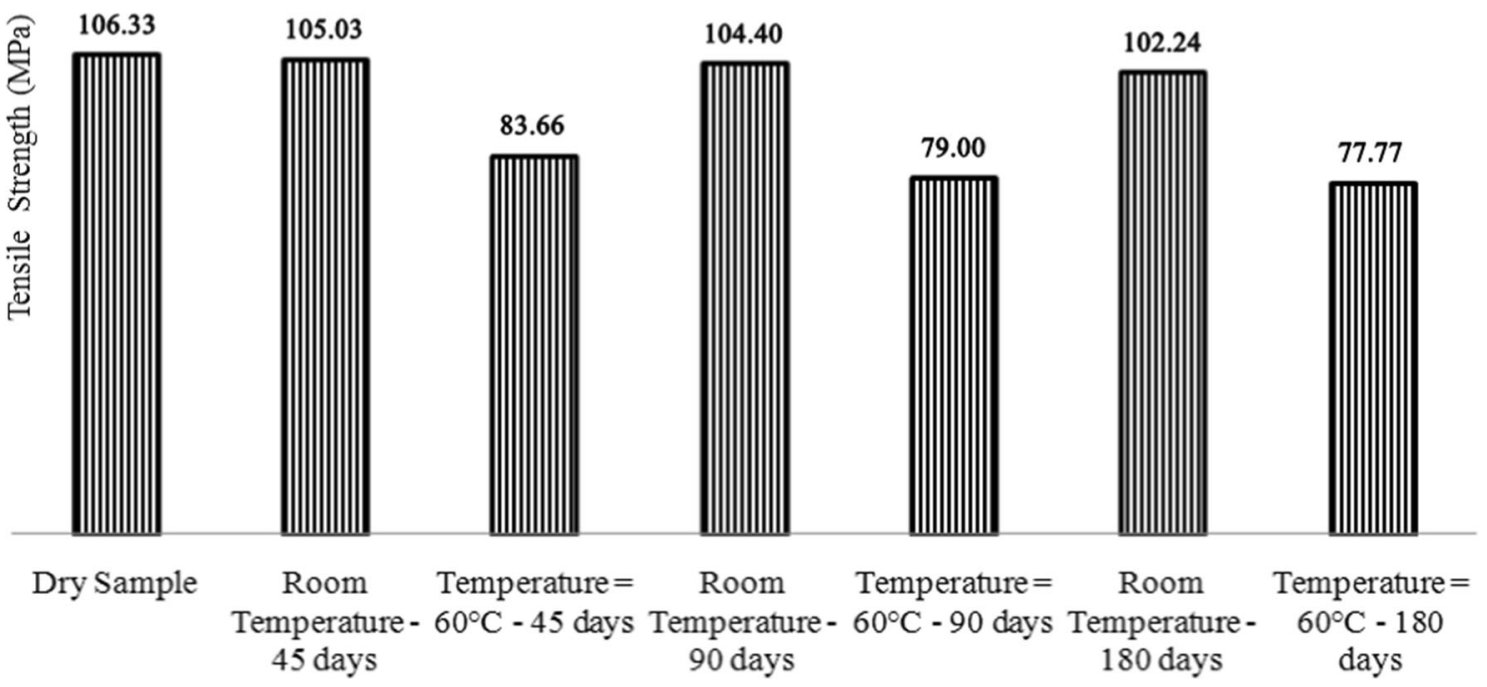

Figure 2 Tensile test results of dry and aged composite glass/epoxy samples. 


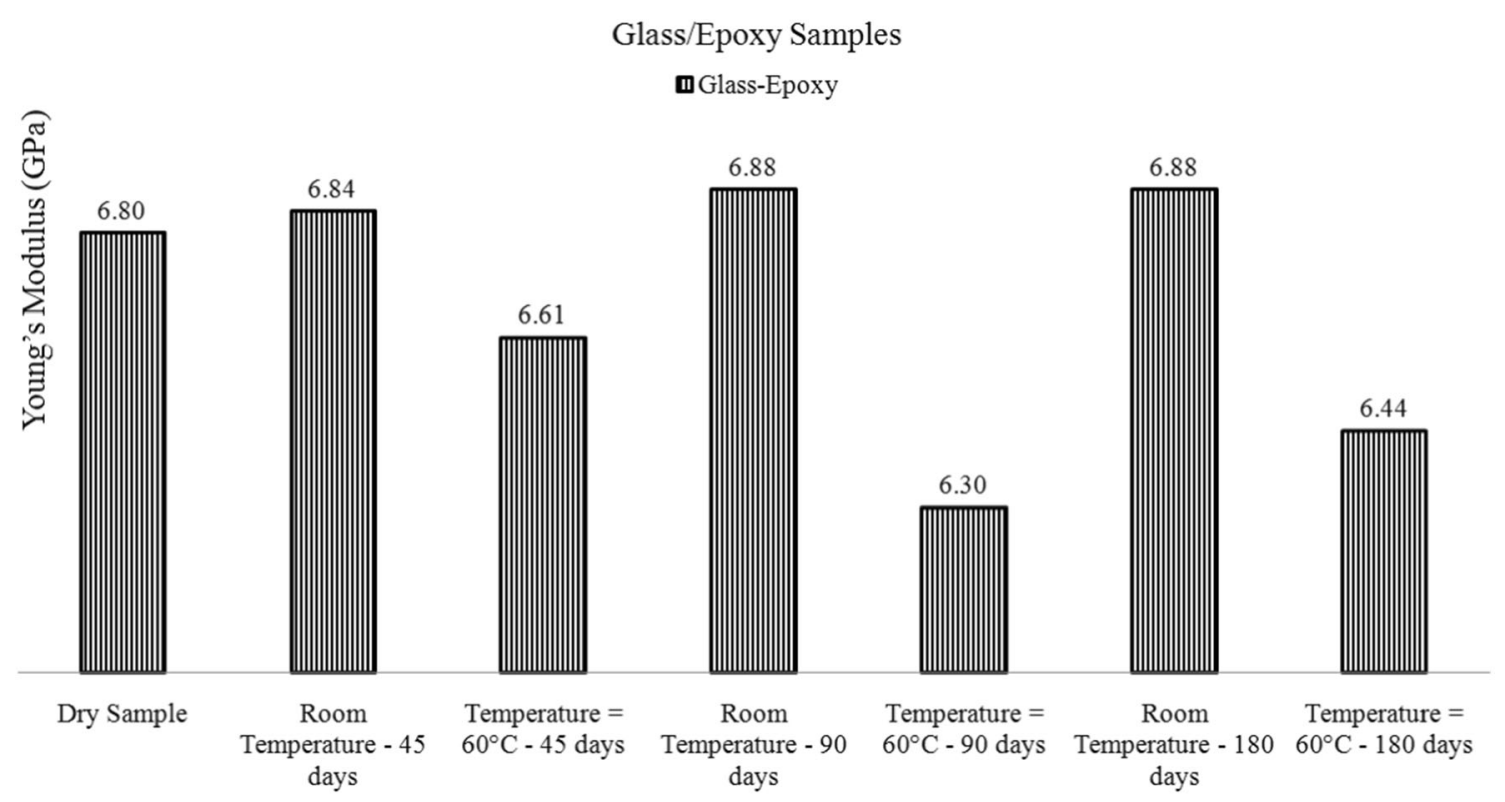

Figure 3 Young's modulus of dry and aged glass/epoxy samples.

\section{Carbon/Epoxy Samples \\ هCarbon-Epoxy}

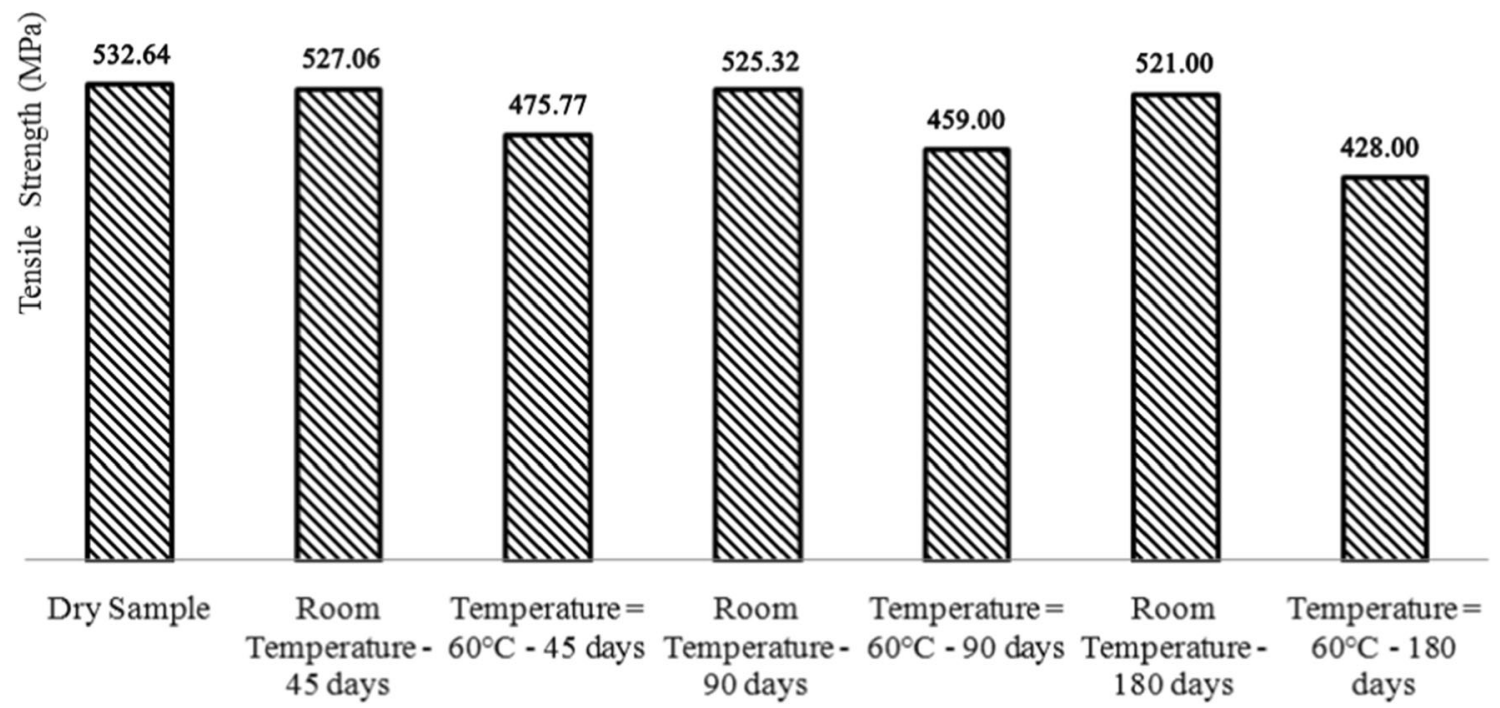

Figure 4 Tensile test results of dry and aged composite carbon/epoxy samples.

showed DGM and explosive gage middle (XGM) failure modes during tensile loading (Fig. 6).

Five single-layer glass/epoxy composite samples were made by hand lay-up with $15 \mathrm{~mm} \times 7.44$ $\mathrm{mm} \times 0.4 \mathrm{~mm}$ dimension, and tested with $2 \mathrm{~mm} /$ min speed thorough Deben micro-test tensile tester [27]. Figure 7 presents stress-strain curves for singlelayer glass/epoxy composite specimens.
The average tensile strength value for these composite specimens was $56.9 \mathrm{MPa}$, while this value was about half of the tensile strength measured through Instron 8800 machine $(106.33 \pm 1.7 \mathrm{MPa})$ with the same epoxy matrix and glass fibre. This reveals that the fibres in the single-layer glass/epoxy specimens with shorter length than tested specimens by Instron machine cannot play their reinforcing role in the composite layer. Additionally, the epoxy matrix in 


\section{Carbon/Epoxy Samples \\ $\mathbf{\Delta C a r b o n - E p o x y}$}

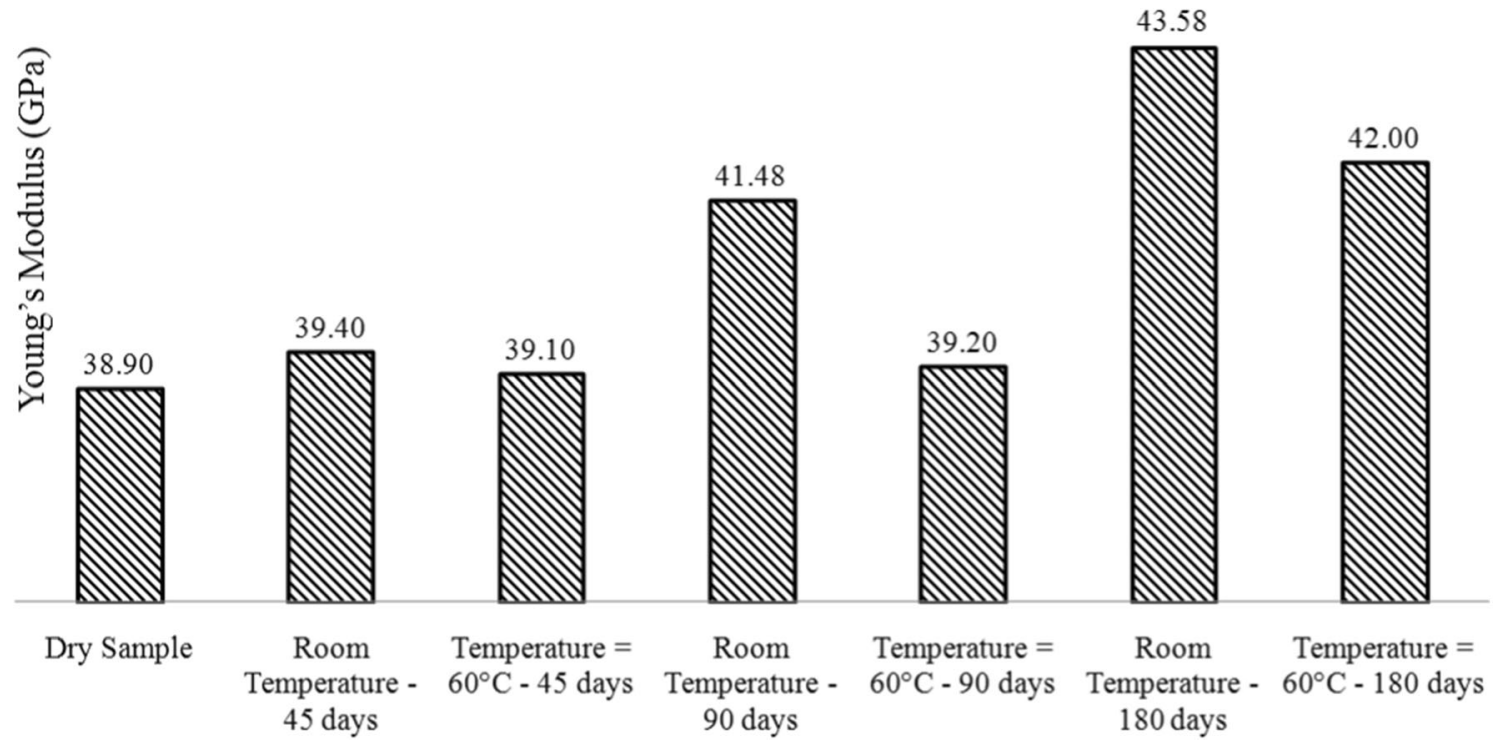

Figure 5 Young's modulus of dry and aged carbon/epoxy samples.

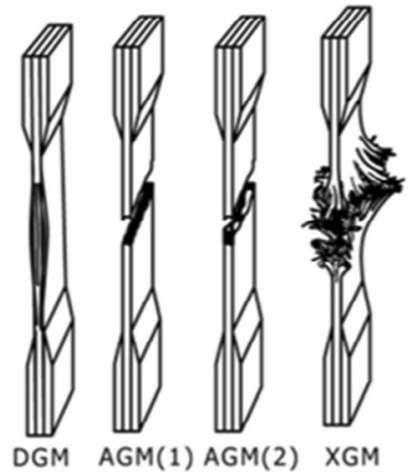

Figure 6 Tensile test failure codes/typical modes [26].

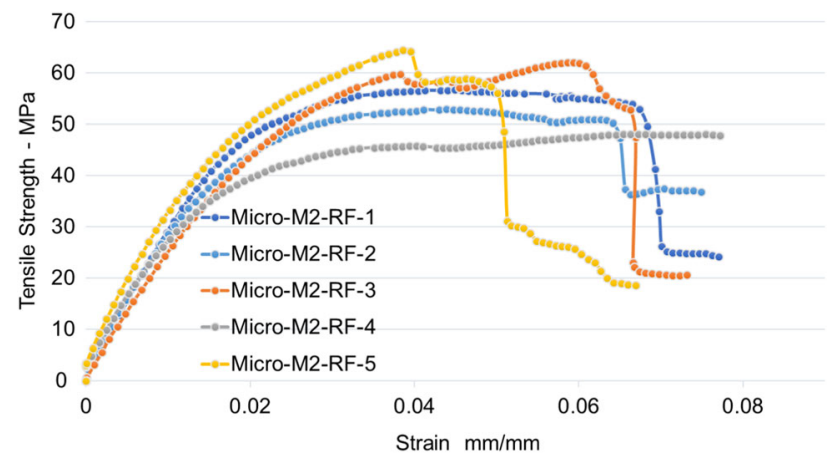

Figure 7 Deben micro-test tensile tester and stress-strain curves for single-layer glass/epoxy specimens. single-layer composite specimens has not been able to appropriately transfer mechanical loads to fibre because of the highly increased fibre volume fraction (more than $70 \%$ ).

According to ASTM D7254 standard [28], composite sheets were cut and tested to measure flexural strength, flexural modulus of elasticity by an Instron 4467 machine at $1 \mathrm{~mm} / \mathrm{min}$ crosshead speed. The stress may be calculated for any point on the loaddeflection curve by the following equation [28]:

$\sigma=\frac{3 P L}{2 b h^{2}}$

where $\sigma$ is stress at the outer surface at mid-span (MPa), $P$, applied force $(\mathrm{N}), L$, support span $(\mathrm{mm}), b$, width of beam $(\mathrm{mm})$, and $h$, thickness of beam $(\mathrm{mm})$. The flexural chord modulus of elasticity was calculated from the stress-strain data by:

$E_{f}^{\text {Chord }}=\frac{\Delta \sigma}{\Delta \varepsilon}$

where $\Delta \sigma$ is difference in flexural stress between the two selected strain points, and $\Delta \varepsilon$ is difference between the two selected strain points (nominally 0.002). The experimental data on flexural tests were calculated by Eqs. 1 and 2, and presented in Figs. 8 and 9. Flexural strength and modulus were determined for dry carbon/epoxy specimens, obtaining a mean value of $631.17 \pm 2 \mathrm{MPa}$ and $34311 \pm 5 \mathrm{MPa}$, 


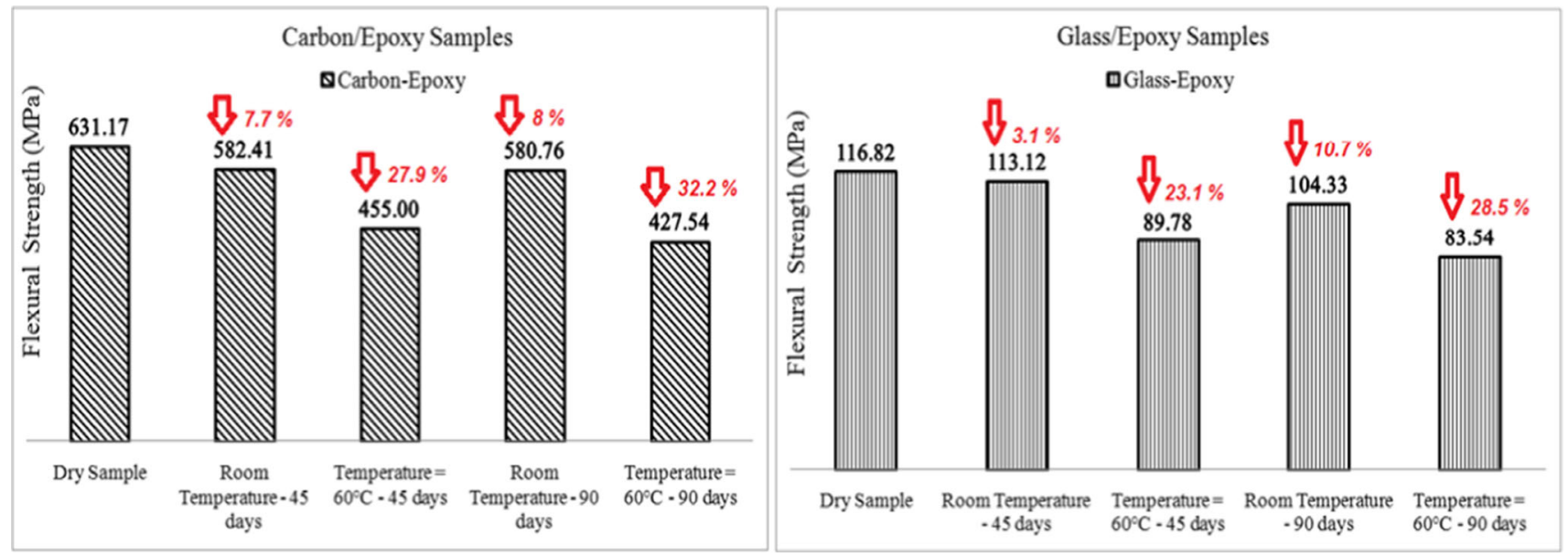

Figure 8 Flexural strength of carbon/epoxy and glass/epoxy specimens.

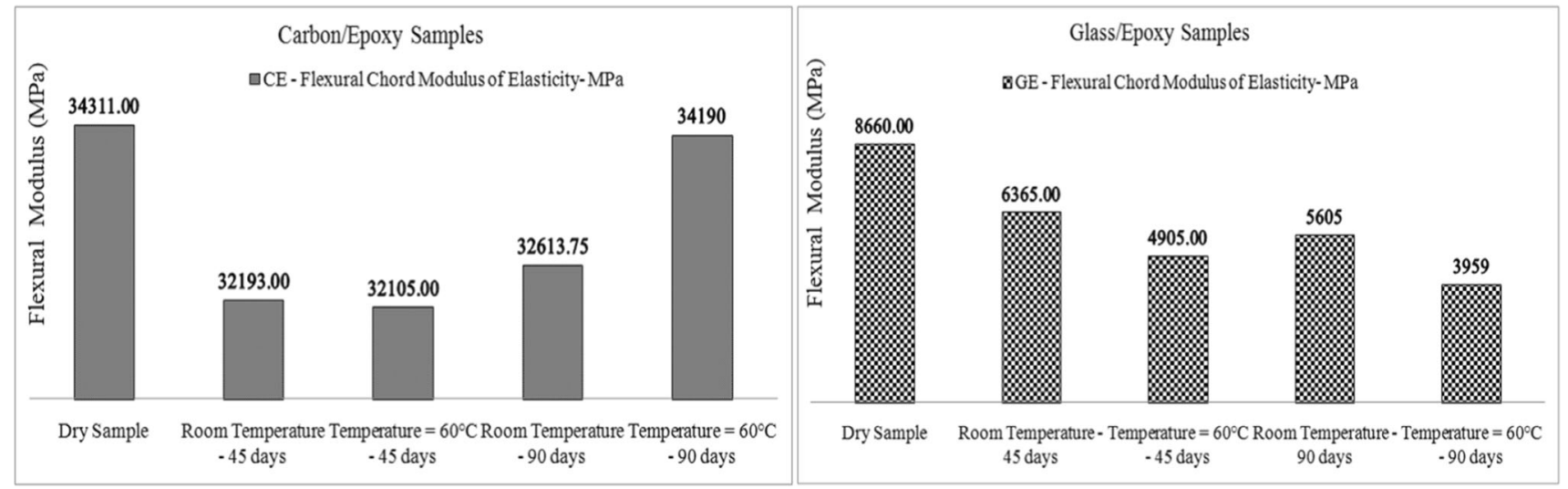

Figure 9 Flexural modulus of carbon/epoxy and glass/epoxy specimens.

respectively. The effect of seawater at room temperature on flexural strength of carbon/epoxy was about $7.7 \%$ loss on this value after 45 days (almost the same value for ageing after 90 days at $60{ }^{\circ} \mathrm{C}$ ). With regard to the flexural properties for the specimens at $60{ }^{\circ} \mathrm{C}$, mean flexural strength and elastic modulus were affected significantly by elevated temperature so that flexural strength decreased to $455 \pm 2.5 \mathrm{MPa}(27.9 \%)$. As can be seen in Fig. 8, after 90 days ageing at $60{ }^{\circ} \mathrm{C}$, flexural strength dropped to $427.54 \pm 2 \mathrm{MPa}(32.2 \%)$ compared to the dry carbon/epoxy sample. As it is illustrated in Figs. 8 and 9, flexural strength and modulus were calculated, measuring a mean value of $116.81 \pm 1.5 \mathrm{MPa}$ and $8660 \pm 4 \mathrm{MPa}$, respectively, for glass/epoxy control specimen. The effect of seawater at room temperature on flexural strength of glass/epoxy was $3.1 \%$ loss in this value after 45 days, whereas a reduction of $8.62 \%(6365 \pm 4 \mathrm{MPa})$ in flexural modulus, respectively were revealed from the experimental work. For glass/epoxy at $60{ }^{\circ} \mathrm{C}$ after 45 days, mean flexural strength and flexural elastic modulus were calculated as $89.77 \pm 2.1 \mathrm{MPa}(23.1 \%)$ for flexural strength and $4905 \pm 3.9 \mathrm{MPa}$ for flexural modulus. The effect of seawater at room temperature on flexural strength of glass/epoxy laminates after 90 days immersion in salt water was about $10.7 \%$ loss and a reduction of $35.2 \%(5605 \pm 4.5 \mathrm{MPa})$ in $\mathrm{E}_{\text {chord }}$. About the flexural properties for the glass/epoxy specimens at $60{ }^{\circ} \mathrm{C}$ after 90 days of degradation in salt water, the flexural strength and flexural elastic modulus were affected significantly by elevated temperature so that flexural strength dropped to $83.54 \pm 2 \mathrm{MPa}$. On the other hand, $\mathrm{E}_{\text {chord }}$ of aged glass/epoxy samples at $60{ }^{\circ} \mathrm{C}$ after 90 days was tested as $3959 \pm 3 \mathrm{MPa}$.

Interlaminar shear strength (ILSS) is a measure of the shear strength between the composite plies and is dominated by matrix/fibre interfacial interactions. 
Shear strength is determined by short beam shear testing (three-point bending). The most widely used test method of ILSS is ASTM D2344, the standard test method for short-beam strength of polymer matrix composite materials and their laminates [29]. Apparent shear strength $(\tau)$ was determined using the force at failure, $F$, in the expression:

$\tau=\frac{3 F}{4 w t}$

where $w$ is the width of the beam and $t$ is the depth of the beam (i.e. thickness), and their product describes the cross-sectional area of the beam. In order to measure the inter-laminar shear strength of the aged glass/epoxy and carbon/epoxy composite samples in the artificial seawater after 90 days at room temperature and the elevated temperature, $60{ }^{\circ} \mathrm{C}$, short beam shear tests were carried out in compliance with ASTM D2344 standard test [29]. The inter-laminar shear strength of composites was determined from test specimens that were tested with the following geometries recommended in ASTM D2344 (Specimen length, $L=$ thickness $\times 6$, and Specimen width, $w=$ thickness $\times 2$ ). The loading nose diameter of the machine jaw was $6 \mathrm{~mm}$, and the roller support diameter of the short beam shear strength test fixture was $3 \mathrm{~mm}$. The test loading speed was set at $1 \mathrm{~mm} /$ $\min$.

Short-beam strength of the samples was calculated as follows:

$F^{\mathrm{sbs}}=0.75 \frac{P_{\mathrm{m}}}{w \times t}$

where $F^{\text {sbs }}$, short-beam strength, $P_{\mathrm{m}}$, maximum load observed during the test, $w$, measured specimen width, $\mathrm{mm}$, and $t$, measured specimen thickness, $\mathrm{mm}$. Since the internal stresses in the specimen are complex and include tension, compression and shear,

Table 5 Failure modes of ILSS tests of glass/epoxy and carbon/ epoxy samples

\begin{tabular}{ll}
\hline Materials & Failure mode \\
\hline Carbon/epoxy-RF & $\mathrm{MS} / \mathrm{PD}$ \\
Glass/epoxy-RF & $\mathrm{PD}$ \\
Carbon/epoxy-T1 & $\mathrm{MS} / \mathrm{PD}$ \\
Glass/epoxy-T1 & $\mathrm{PD} / \mathrm{TF}$ \\
Carbon-T2 & $\mathrm{MS} / \mathrm{PD}$ \\
Glass-T2 & $\mathrm{PD} / \mathrm{TF}$ \\
\hline
\end{tabular}

MS multi-shear, $P D$ plastic deformation, and TF tension failure a variety of failure modes can occur. Table 5 indicates the failure modes at tested glass/epoxy and carbon/ epoxy composite samples. It is apparent that multishear and plastic deformation are the most dominant failure modes in the aged composite specimens. It is evident from the experimental results presented in Fig. 10 that interlaminar shear strength (ILSS) values decreased over water immersion time. After ageing time of 90 days, the decrease in ILSS was $5.4 \%$ and $1 \%$ for the glass/epoxy and carbon/epoxy which were at room temperature, respectively. In addition to this, after 90 days ageing at $60{ }^{\circ} \mathrm{C}$, the losses in ILSS of the glass/epoxy and carbon/epoxy composites were measured to be $30.3 \%$ and $8.3 \%$, respectively. The decrease in ILSS as well as the other mechanical properties after water immersion can be connected to the weak fibre-matrix interface due to water absorption into the composite specimens especially in glass/epoxy samples which had higher void content (based on the microscopic images, see "Microscopy" section) in comparison with carbon/ epoxy samples.

Also, a Keysight Nanoindenter G200 machine with a Berkovich indentor (in Compliance with ISO 14577) was utilized to measure hardness of glass/epoxy and carbon-epoxy at room temperature and elevated temperature (Fig. 11).

\section{Differential scanning calorimetry (DSC)}

The DSC measurements were performed using a DSC 214 Polyma system with software Proteus ${ }^{\circledR} 7.0$ manufactured by NETZSCH with an air flow of $50 \mathrm{~mL} / \mathrm{min}$. Glass transition temperatures $(\mathrm{Tg})$ for the composite materials were calculated in accordance with ASTM D3418-12 [30]. A temperature scan was performed on less than $10 \mathrm{mg}$ composite

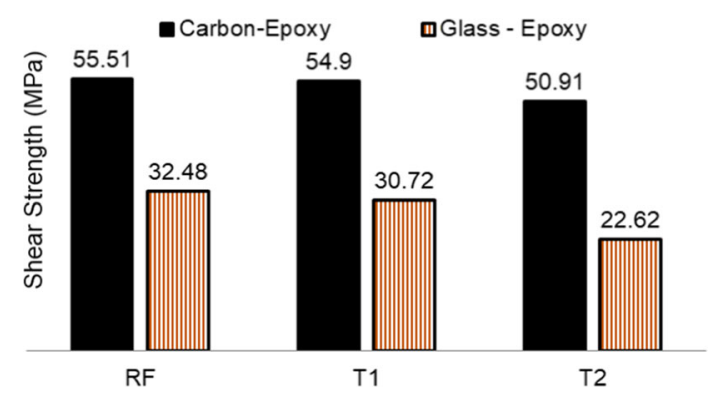

Figure 10 Comparison of ILSS experimental data for glass/epoxy and carbon/epoxy samples. $\mathrm{RF}=$ reference sample, $\mathrm{T} 1=$ room temperature, and $\mathrm{T} 2=60{ }^{\circ} \mathrm{C}$. 


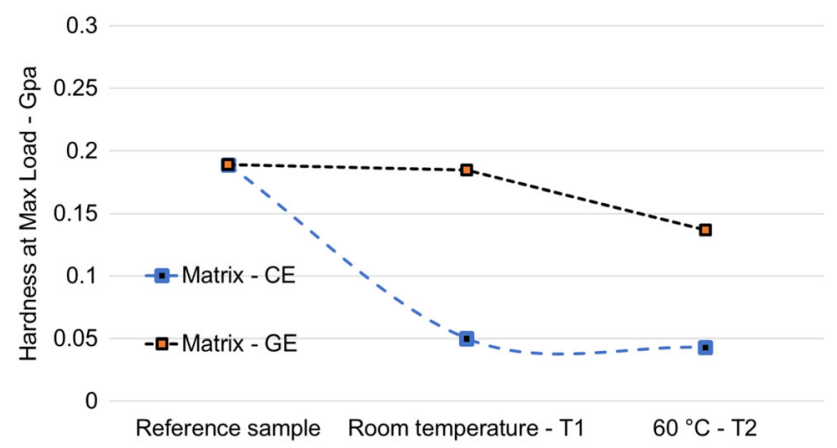

Figure 11 Hardness nanoindentation results for matrix cells (standard test), $\mathrm{CE}=$ carbon/epoxy, GE = Glass/epoxy.

samples from 40 to $250{ }^{\circ} \mathrm{C}$ at a heating rate of $20{ }^{\circ} \mathrm{C} /$ min. Three samples of each group, control and aged specimens in saltwater after 180 days at room temperature and $60{ }^{\circ} \mathrm{C}$, were first heated from 40 to $250{ }^{\circ} \mathrm{C}$. For the second scan, the samples were cooled from 250 to $40{ }^{\circ} \mathrm{C}$; in the last scan, the samples were again heated to $250{ }^{\circ} \mathrm{C}$ and then cooled to $40{ }^{\circ} \mathrm{C}$. For all scans, the samples were held for $5 \mathrm{~min}$ at $40{ }^{\circ} \mathrm{C}$ and at $250{ }^{\circ} \mathrm{C}$. Table 6 shows the effect of ageing process on $\mathrm{Tg}$ for composite specimens that have been immersed in salt water for a prolonged period (180 days) of time at two different temperatures. It is evident from Table 6 that the glass transition temperature, $\mathrm{Tg}$, measured via DSC for glass/epoxy samples decreased slightly as the exposure temperature increased from room temperature to $60^{\circ} \mathrm{C}$.

The $\mathrm{Tg}$ values for glass/epoxy and carbon/epoxy composite samples decreased about 2\% with increasing temperature of hydrothermal exposures after 180 days. This reduction in $\mathrm{Tg}$ is induced by plasticization (softening) of the polymer matrix.

\section{Microscopy}

Grinding and polishing procedure shown in Table 7 was carried out on the specimens using the Buehler automet 250 machine. The surface roughness measurements of the bulk matrix regions of the samples were carried out using the Dimension 3100 atomic force microscope (AFM). Three separate $10 \times 10 \mu \mathrm{m}$ areas of the bulk matrix surface were scanned in contact mode. The mean surface roughness (Ra) measured from the AFM scans was $3.9 \pm 0.4 \mathrm{~nm}$.

Microscopic images were obtained using a light microscopy instrument and assessed through image processing techniques. The prepared samples were studied under microscopy to find the ageing process signs such as matrix degradation, fibre/matrix debounding, etc. under microscope as well as measuring fibre volume fraction and void content in the composite samples. A portable USB Digital Microscope with $400 \times-1000 \times$ magnification was used to preliminarily monitor the surface of composite specimens after cutting and polishing. The Olympus BX51M microscope offers a full product line-up for every purpose and even for special material science applications [31]. The UC30 camera provides an excellent 3.2-megapixel resolution and fast frame rates with the added benefit of $2 \times$ and $3 \times$ color binning. OLYMPUS Stream can easily be customized and provides sophisticated results with simple flexible operation. The UC30 can be fully operated via OLYMPUS Stream image analysis software. Figure 12 shows the matrix cracking and fibre debounding in the near-surface layers of aged composite specimens at $60{ }^{\circ} \mathrm{C}$ after 90 days in salt water. The microscopic images did not indicate any tangible cracking in the epoxy matrix reinforced by glass or carbon fibres over 90 days ageing process at room temperature, while for those samples immersed in salt water at $60{ }^{\circ} \mathrm{C}$, debonding between fibre and matrix in glass/epoxy samples, and matrix cracking in carbon/epoxy specimens was observed.

The average area fraction in different polished layers of different dry glass/epoxy and carbon/ epoxy samples was calculated via ImageJ software to illustrate the average volume fraction of fibres and void content in control samples (Fig. 13). Average values for fibre volume fraction and void content in the composite specimens are listed in Table 8. The volume fraction of fibre in reference carbon/epoxy sample was calculated about $60 \%$, whereas the void content was less than $0.2 \%$. The voids in glass/epoxy
Table 6 Glass transition temperature calculated from DSC test

\begin{tabular}{llll}
\hline Carbon-epoxy & $\operatorname{Tg}\left({ }^{\circ} \mathrm{C}\right)$ & Glass-epoxy & $\operatorname{Tg}\left({ }^{\circ} \mathrm{C}\right)$ \\
\hline Dry/control sample & 81.00 & Dry sample & 107.15 \\
Room temperature-180 days & 80.80 & Room temperature-180 days & 106.60 \\
$60{ }^{\circ} \mathrm{C}-180$ days & 79.30 & $60{ }^{\circ} \mathrm{C}-180$ days & 105.01 \\
\hline
\end{tabular}


Table 7 Sample preparation (polishing process)

\begin{tabular}{lllll}
\hline Surface & Lubricant & Time (min) & Force/specimen (N) & Speed (RPM): base-head \\
\hline SiC-P320 & Water & $2: 00$ & Manual & - \\
SiC-P800 & Water & $2: 00$ & Manual & - \\
SiC-P1200 & Water & $2: 00$ & Manual & - \\
Microcloth & Diamond suspension $9 \mu \mathrm{m}$ & $5: 00$ & $25 \mathrm{~N}$ & $200-30$ \\
Microcloth & Diamond suspension $3 \mu \mathrm{m}$ & $5: 00$ & $20 \mathrm{~N}$ & $200-30$ \\
Microcloth & Diamond suspension $0.05 \mu \mathrm{m}$ & $2: 00$ & $20 \mathrm{~N}$ & $150-30$ \\
\hline
\end{tabular}

Figure 12 Matrix cracking and fibre de-bounding in the aged composite specimens at $60{ }^{\circ} \mathrm{C}$, glass/epoxy (top), carbon/epoxy (bottom).

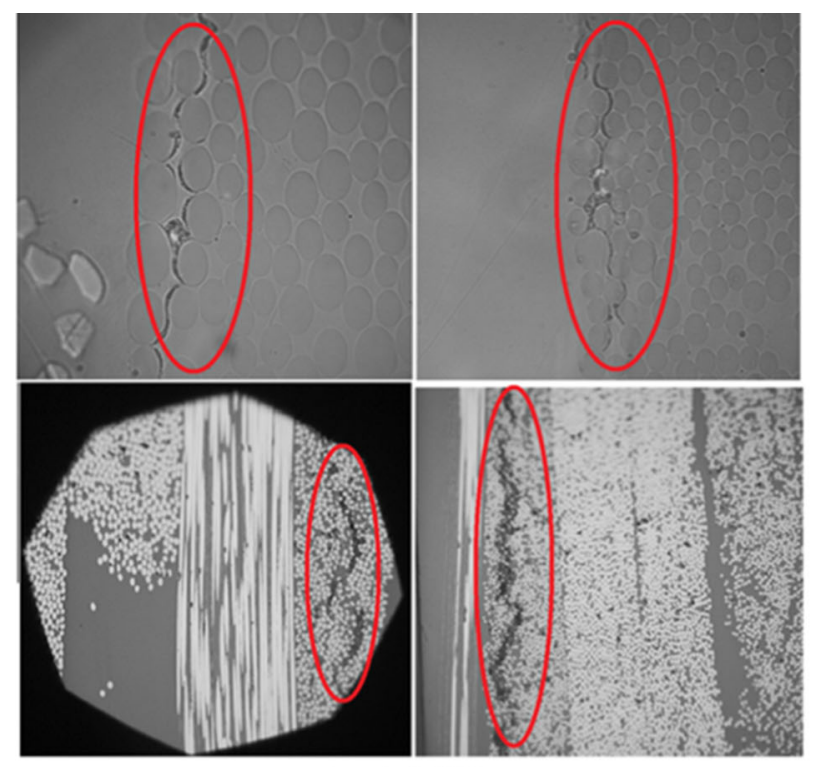

Aged at $60 \mathrm{C}$
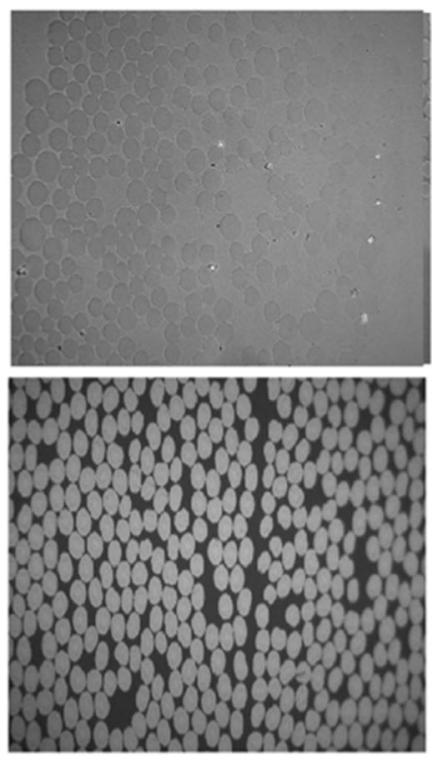

Reference Samples
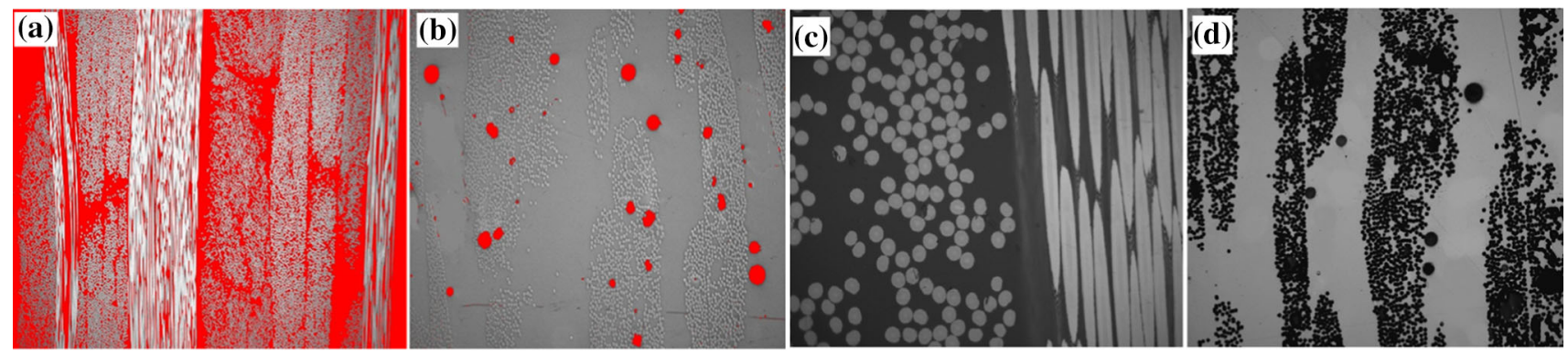

Figure 13 A Fibre volume fraction calculation in a carbon/epoxy sample, B void content measurement in a glass/epoxy specimen, C low void in carbon/epoxy samples, and $\mathbf{D}$ fibre volume fraction in glass/epoxy specimens.

samples are apparently shown in Fig. 13B (red circles) so that this value was measured as $2.83 \%$. Since hand lay-up method was used in the manufacturing process of glass/epoxy specimens, it was predictable that the fibre volume fraction would be less than $50 \%$ which in this case it was calculated just about $35 \%$.
In addition, micro-CT scanning has been carried out via SCANCO Medical $\mu$ CT-100 with a voxel resolution of $16 \mu \mathrm{m}$ in order to confirm the volume fraction and void content data indicated by microscopic imaging of the composites microstructure. A volume fraction analysis of the three specimens was carried out using ImageJ Fiji software on the CT scan 
Table 8 Average values of fibre volume fraction and void content in the composite specimens

\begin{tabular}{lcl}
\hline Material & Void content (\%) & Fibre fraction (\%) \\
\hline Carbon/epoxy & $<0.2$ & 59.91 \\
Glass/epoxy & 2.83 & 34.84 \\
\hline
\end{tabular}

data (Fig. 14). The technique allows the determination of material phases of varying density via the attenuation of X-rays as they pass through a specimen. This facilitates a quantitative characterisation of the void volume content of the specimens, as well as a qualitative investigation of fibre tows, stitching and resin-rich areas.

Generally, the values calculated for fibre volume fraction from micro-CT were 4-5\% higher than what measured by microscopic imaging. This is because of higher resolution and quality of images captured by microscope, so that every single fibre was apparently detectable, whereas, in the images of different layers of carbon/epoxy samples, just yarns were traceable (Fig. 15). On the other hand, the resolution of images was not good enough to calculate the volume fraction of fibres in glass/epoxy samples as well as the void content in both glass/epoxy and carbon/epoxy test samples.

\section{Degradation mechanisms}

Mechanical-based damages such as plasticization and swelling are the main physical degradation of polymer resins, which may result in softening in the polymer/composite, decreasing its mechanical properties such as tensile strength, ILSS, flexural properties, etc. Water penetration can also lead to hydrolysis of epoxy resin showing that the fibre/matrix interface is degraded. In addition, Chemical-based mechanisms result in changes to the polymer matrix that are not reversible and occur primarily due to hydrolytic degradation, whereby the diffusion of water into the composite results in chain scission.

It is worth noting that in spite of reaching saturation point in carbon/epoxy composites at $60{ }^{\circ} \mathrm{C}$ ("Results and discussion" section, 42 days), there is still change in mechanical properties after 45 days, 90 days and 180 days which is a challenging issue in the design process and material selection for applications under water. This shows that even after water penetration into the samples and reaching the saturation point (and mechanical-based damages), water molecules still react with the epoxy over time, and cause irreversible chemical changes (chain scission,
Figure14 $\mu \mathrm{CT}$ images of carbon/epoxy and glass/epoxy composite samples.
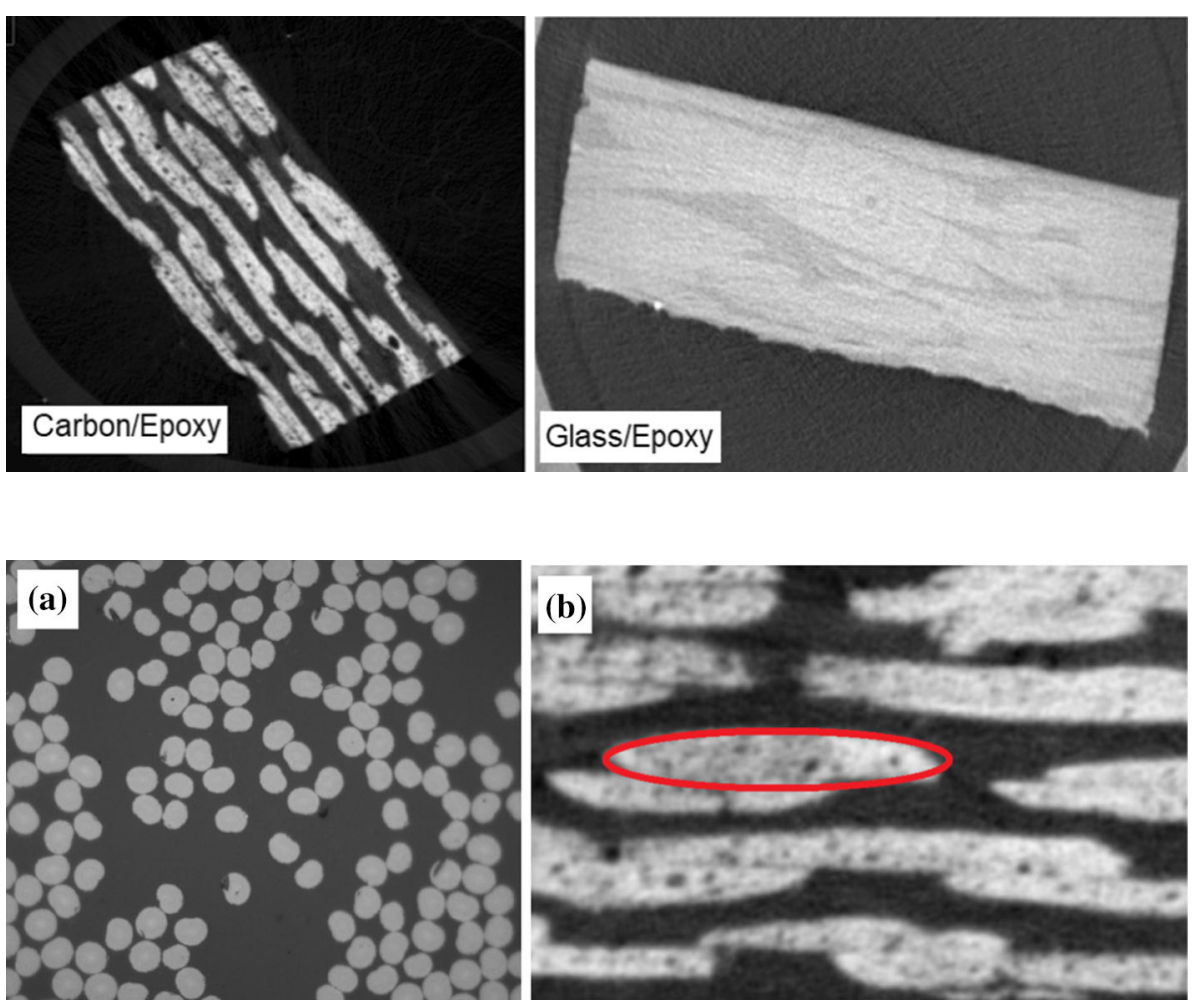

Figure15 A Microscopic imaging with $100 \mathrm{X}$ magnification, B yarns in micro-CT imaging. 
chemical-based damages), and diminish performance. The results for carbon/epoxy laminates aged at elevated temperature showed that chemical changes in matrix, and in turn, weak interfacial bonding between fibre/matrix (after reaching the maximum water content after 42 days) have higher effect on the mechanical properties (such as tensile strength) than initial induced stress by water (osmotic and capillary phenomenon). An evidence of this is that the maximum water uptake by carbon/epoxy composites was just $0.61 \%$ confirmed by low void content in carbon/ epoxy samples, while after the saturation time $20 \%$ loss in tensile strength, $32 \%$ loss in the flexural strength, and $8.3 \%$ loss in ILSS were observed. As the carbon/epoxy samples at room temperature reached the maximum water uptake after 72 days, it is likely that change in the mechanical properties at room temperature after 45 days is affected by both water uptake (osmotic process, capillary phenomenon) and degradation in matrix (chemical-based degradation). By continuing the ageing time over the saturation time (72 days), the reaction between water molecules and the epoxy matrix resulting in higher degradation in the matrix plays a more significant role in decreasing mechanical properties (there is no change in water content absorbed by composite samples) like what was observed from the carbon/epoxy composites at $60{ }^{\circ} \mathrm{C}$.

The same discussion is valid for the ageing process in glass/epoxy samples at elevated temperature so that the saturation time is 80 days while there is still a significant change in mechanical properties after 90 days and 180 days (there is no change in water content). With regard to the immersed glass/epoxy composites at room temperature that the saturation occurred at moisture content $1.13 \%$ (same as aged samples at $60^{\circ} \mathrm{C}$ ) and after 245 days, a relatively slight change was observed over the immersion time $(45,90$, and 180 days) before the saturation time.

Generally, during water penetration into the voids and micro-cracks in the composite samples the existence of a high -OH group, especially after reaching the saturation point, fibers which are now under attack of water molecules (there is no matrix to protect them) present low moisture resistance resulting in poor interfacial fibre/matrix bonds leading drop in the mechanical properties such as the experimental results of this work. As a result, it is notable that the higher ageing time and temperature, the higher change in mechanical properties.
As mentioned earlier, ageing process on composite materials in presence of water and temperature results in plasticization and swelling stress (due to the absorbed water by composite laminate), in turn, decrease the glass transition temperature. In some cases, $\mathrm{Tg}$ of polymeric materials depends on the level of cross-linking density that can increase during ageing process in elevated temperatures. Because of imperfect curing/cross-linking of the polymer, some voids could have been created in the polymer (it was discussed in the previous sections). The Tg deterioration is affected when the extent of free volume/ voids increase. Hence, it may be achieved that, on long-time hydrothermal process, polymer matrix could be affected by chemical-based degradation and plasticization leading to chain scission/breaking. Since in this research, the composite materials were post-cured at $60{ }^{\circ} \mathrm{C}$ (equal to the elevated temperature in this research) it is unlikely to experience crosslinking in polymer matrix during ageing process. Therefore, the main reason for the reduction in glass transition temperature over immersion time might be plasticization and softening in epoxy (matrix) which was confirmed by reduction in hardness of the composite samples over time through nano-indentation test (Fig. 11). From Fig. 11, it can be concluded that the hardness amount for the reference glass/ epoxy specimen is $0.189 \mathrm{GPa}$, and the aging process has made a $2.1 \%(0.185 \mathrm{GPa})$ loss in this value at room temperature and $27.51 \%(0.137 \mathrm{GPa})$ at $60{ }^{\circ} \mathrm{C}$. Also, it can be seen that the reference carbon/epoxy and glass/epoxy specimens (0.189 GPa) are identical in terms of hardness, but the aging process resulted in higher decrease in hardness properties of carbon/ epoxy in comparison with that value of glass/epoxy so that there is $73.5 \%(0.05 \mathrm{GPa})$ reduction after 90 days degradation at room temperature in saltwater, and $77.2 \%(0.43 \mathrm{GPa})$ at $60{ }^{\circ} \mathrm{C}$.

The difference between results for glass/epoxy and carbon/epoxy samples is associated with the difference in their materials (matrix and fibre), void content, fibre volume fraction and, in turn, the difference in the amount of water absorbed by glass/epoxy and carbon/epoxy samples. 


\section{Conclusion}

Mechanical testing and physicochemical characterisation of dry and aged glass/epoxy and carbon/ epoxy composites in salt water at room temperature and $60{ }^{\circ} \mathrm{C}$ have been conducted in order to assess the effect of ageing process on degradation in composite laminates.

The primary conclusions of the study are:

- Experimental results revealed that the change in Young's modulus over ageing process after 45 $(6.84 \pm 0.3 \mathrm{GPa}), 90(6.88 \pm 0.3 \mathrm{GPa})$, and 180 $(6.88 \pm 0.3 \mathrm{GPa})$ days at room temperature indicating no significant change in this value for glass/epoxy, as for the dry sample was $6.8 \pm 0.3$ GPa. The ageing process on glass/epoxy composite sheets at $60{ }^{\circ} \mathrm{C}$ shows a fluctuation in Young's modulus, $6.61 \pm 0.3 \mathrm{GPa}$ after 45 days, $6.3 \pm 0.3$ GPa after 90 days, and $6.44 \pm 0.3 \mathrm{GPa}$ after 6 months showing a slight change in module of elasticity. The explanation of this achievement is that the degradation process affects tensile strength concurrently with strain in the same way, so that the module of elasticity is almost constant with a slight fluctuation.

- The effect of seawater on tensile strength of carbon/epoxy composite samples after 90 and 180 days at elevated temperature was significant. A rise in tensile elastic modulus due to seawater ageing, $6.6 \%$ at an elevated temperature after 90 days, and $7.96 \%$ after 180 days was observed, different from the trend shown by the results for glass/epoxy samples.

- The effect of seawater at room temperature on flexural strength and modulus of glass/epoxy were $3.1 \%$ and $8.62 \%$ loss after 45 days. The flexural strength of glass/epoxy laminates after 90 days immersion in salt water at room temperature dropped $10.7 \%$, whereas a reduction of $35.2 \%$ in $E_{\text {chord, }}$ was indicated.

- After ageing time of 90 days, the decrease in ILSS was $5.4 \%$ and $1 \%$ for the glass/epoxy and carbon/ epoxy at room temperature, respectively. After 90 days ageing at $60{ }^{\circ} \mathrm{C}$, the drops in ILSS of the glass/epoxy and carbon/epoxy composites were measured to be $30.3 \%$ and $8.3 \%$, respectively.

- Glass transition temperature of dry carbon/epoxy composite was calculated as $81^{\circ} \mathrm{C}$, while after 180 days ageing at room temperature and $60^{\circ} \mathrm{C}$ dropped o $80.8^{\circ} \mathrm{C}$ and $79.3^{\circ} \mathrm{C}$, respectively. In the same way, $T_{\mathrm{g}}$ for dry glass/epoxy laminates, aged at room temperature, and $60{ }^{\circ} \mathrm{C}$ was measured as 107.15 ${ }^{\circ} \mathrm{C}, 106.6^{\circ} \mathrm{C}$ and $105.01{ }^{\circ} \mathrm{C}$, respectively.

- Change in mechanical properties occurs even after reaching the saturation point in both glass/epoxy and carbon-epoxy laminates.

- Effect of chemical-based degradation (reaction between water and epoxy, chain scission) on the loss in mechanical properties of composite samples is higher than the effect of the mechanicalbased damages (induced stress by water absorption, capillary and osmosis phenomenon).

- The experimental data of the hardness change confirms the degradation in the matrix (Epoxy) during ageing process in saltwater, whereby the change (decrease) in glass transition temperature was affirmed.

\section{Acknowledgements}

The authors would like to express their gratitude to David Connolly for carrying out the X-ray CT scans at NUI Galway and Eric McNiffe for providing AFM data.

\section{Funding}

Open Access funding provided by the IReL Consortium. This research was funded by Enterprise Ireland through the Irish Composite centre (IComp), Degradation of Composites (DeCay) project (Grant No. TC2014-0017).

\section{Declarations}

Conflict of interest The author(s) declared no potential conflicts of interest with respect to the research, authorship, and/or publication of this article.

Open Access This article is licensed under a Creative Commons Attribution 4.0 International License, which permits use, sharing, adaptation, distribution and reproduction in any medium or format, as long as you give appropriate credit to the original author(s) and the source, provide a link to the Creative Commons licence, and indicate if changes were 
made. The images or other third party material in this article are included in the article's Creative Commons licence, unless indicated otherwise in a credit line to the material. If material is not included in the article's Creative Commons licence and your intended use is not permitted by statutory regulation or exceeds the permitted use, you will need to obtain permission directly from the copyright holder. To view a copy of this licence, visit http://creativecommons.org/licen ses/by/4.0/.

\section{References}

[1] The roadmap for transforming the EU into a competitive, low-carbon economy by 2050 . https://ec.europa.eu/clima/site s/clima/files/2050_roadmap_en.pdf

[2] The DeCay project final report, Irish Composites Centre, 2020

[3] Alam P, Robert C, Brádaigh CMÓ (2018) Tidal turbine blade composites - a review on the effects of hygrothermal aging on the properties of CFRP. Compos B Eng 149:248-259

[4] Summerscales J (2014) Durability of composites in the marine environment. Solid Mech Appl 208:1-13. https://doi. org/10.1007/978-94-007-7417-9-1

[5] Varga M, Kopecký D, Kopecká J, Křivka I, Hanuš J, Zhigunovc A, Trchová M, Vrňata M, Prokeš J (2017) The ageing of polypyrrole nanotubes synthesized with methyl orange. Eur Polymer J 96:176-189

[6] Miller D, Mandell JF, Samborsky DD, Hernandez-Sanchez BA, Griffith DT (2012) Performance of composite materials subjected to salt water environments. AIAA SDM Wind Energy Session, 53rd AIAA/ASME/ASCE/AHS/ASC structures, structural dynamics and materials conference, 23 April 2012-26 April 2012, Honolulu, Hawaii

[7] Mansouri L, Djebbar A, Khatir S, Wahab MA (2019) Effect of hygrothermal aging in distilled and saline water on the mechanical behaviour of mixed short fibre/woven composites. Compos Struct 207:816-825

[8] Trofimchuk ES, Moskvina MA, Nikonorova NI, Efimov AV, Garina ES, Grokhovskaya TE, Ivanova OA, Bakirov AV, Sedush NG, Chvalun SN (2020) Hydrolytic degradation of polylactide films deformed by the environmental crazing mechanism. Eur Polym J 139:110000

[9] Fang T, Yihui P, Zheng Z (2017) A long-term mechanical degradation model of unidirectional natural fiber reinforced composites under hydrothermal ageing. Compos Sci Technol 142:156-162

[10] Ghabezi P, Harrison N (2020) Mechanical behavior and long-term life prediction of carbon/epoxy and glass/epoxy composite laminates under artificial seawater environment. Mater Lett 261:127091

[11] Kant M, Penumadu D (2011) Sea Water Effects on ultimate tensile and fracture strength of carbon fibers with nanotensile testing. 18th International conference on composite materials, in Jeju Island, Korea

[12] Limsukon W, Auras R, Selke S (2019) Hydrolytic degradation and lifetime prediction of poly(lactic acid) modified with a multifunctional epoxy-based chain extender. Polym Test 80:106108

[13] Tserpes K, Tzatzadakis V, Katsiropoulos C (2019) Effect of hygrothermal ageing on the interlaminar shear strength of carbon fiber-reinforced rosin-based epoxy bio-composites. Compos Struct 226:111211

[14] Bauer KN, Liu L, Wagner M, Andrienko D, Wurm FR (2018) Mechanistic study on the hydrolytic degradation of polyphosphates. Eur Polymer J 108:286-294

[15] Gagani AI, Monsås AB, Krauklis AE, Echtermeyer AT (2019) The effect of temperature and water immersion on the interlaminar shear fatigue of glass fiber epoxy composites using the I-beam method. Compos Sci Technol 181:107703

[16] Wright DC (2001) Failure of plastics and rubber productscauses, effects and case studies involving degradation. RAPRA Technology Report, ISBN: 1-85857-261-8

[17] Maxwell AS (2005) Review of techniques for monitoring the environmental, degradation of polymers. NPL Report DEPC MPR 015

[18] Davies P (2016) Environmental degradation of composites for marine structures: new materials and new applications. Philos Trans R Soc Math Phys Eng Sci

[19] Wang WH, Huang CW, Tsou EY, Ao-Ieong WS, Hsu HC, Wong DSH, Wang J (2021) Characterization of degradation behavior of poly(glycerol maleate) films in various aqueous environments. Polym Degrad Stability 183:109441

[20] Chakraverty AP, Mohanty UK, Mishra SC, Satapathy A (2015) Sea Water Ageing of GFRP Composites and the Dissolved salts. IOP conference series: materials science and engineering, volume 75 , conference 1

[21] Chakraverty AP, Mohanty UK, Mishra SC, Biswal BB (2016) Effect of hydrothermal immersion and hygrothermal conditioning on mechanical properties of GRE composite. IOP conference series: materials science and engineering, volume 178, National Conference on Processing and Characterization of Materials 9-10 December 2016, NIT Rourkela, Orissa, India

[22] Deroiné M, Duigou AL, Corre YM, Le Gac PY, Davies P, César G, Bruzaud S (2014) Accelerated ageing and lifetime prediction of poly(3-hydroxybutyrate-co3-hydroxyvalerate) in distilled water. Polym Test 39:70-78 
[23] https://www.nasa.gov/mission_pages/aquarius/multimedia/g allery/pia14786.html

[24] www.easycomposites.co.uk

[25] ASTM D 5229/D 5229M, Standard Test Method for Moisture Absorption Properties and Equilibrium Conditioning of Polymer Matrix Composite Materials, Published March 2004

[26] ASTM D3039/D3039M, Standard Test Method for Tensile Properties of Polymer Matrix Composite Materials, Published November 2017, Originally approved in 1971

[27] https://deben.co.uk/

[28] D7264/D7264M, Standard Test Method for Flexural Properties of Polymer Matrix Composite Materials, Published May 2015. Originally, approved in 2006
[29] ASTM standard: D2344/D2344M - 16, Standard Test Method for Short-Beam Strength of Polymer Matrix Composite Materials and Their Laminates

[30] ASTM D3418 - 12, Standard Test Method for Transition Temperatures and Enthalpies of Fusion and Crystallization of Polymers by Differential Scanning Calorimetry

[31] https://www.microscopesales.co.uk/olympus-microscopes/ol ympus-bx51m.html. Accessed 15 March 2021

Publisher's Note Springer Nature remains neutral with regard to jurisdictional claims in published maps and institutional affiliations. 